\title{
Nutritional and Medicinal Properties of Stevia Rebaudiana
}

\author{
Fasiha Ahsan*, Shahid Bashir and Faiz-ul-Hassan Shah \\ University Institute of Diet and Nutritional Sciences, The University of Lahore, Pakistan
}

Submission: June 25, 2020; Published: July 16, 2020

*Corresponding author: Fasiha Ahsan, PhD Scholar, University Institute of Diet and Nutritional Sciences, The University of Lahore, Pakistan

\begin{abstract}
Researches on new molecules with the least toxic effects and better potency is on its way and more attention is being given upon medicinal plants for forcing away the above problems. Medicinal plants have been recognized as potential drug candidates. Stevia, a natural sweetener with medicinal properties and also having nutritional, therapeutic and industrial importance is being used all over the world. Stevia rebaudiana leaves are usually referred to as candy, sweet and honey leaves. Diterpene glycosides are responsible for its high sweetening potential of leaves. The phytochemical properties of bioactive chemicals present in stevia leaves are involves in maintaining the physiological functions of human body. Paper also highlights the importance of nutritional aspects of dried stevia leaves, metabolism of stevia, effects of it consumption on human health and clinical studies related to stevia ingestion. Various medicinal properties of stevia leaves discussed in paper like anti-hyperglycemia, anti-oxidative, hypotensive, nephro-protective, hepato protective, antibacterial and antifungal. Basic purpose of this review to understand the medicinal potential of stevia and its acceptance as a significant raw material for human diet.
\end{abstract}

Keywords: Stevia; Diabetes; Phytochemicals; Medicinal plant; Steviol; Nutrition; Disorders

Abbreviations: TGF- $\beta$ : Transforming Growth Factor; $\beta$; PCT: Proximal Convoluted Tubule; DCT: Distal Convoluted Tubule; PCC: Protein Carbonyl Content; BHA: Butylated Hydroxyanisole; BHT: Butylated Hydroxytoluene; DPPH: Diphenyl-1-Picrylhydrazyl-Hydrate; FRAP: Ferric Ion Reducing Activity; ROS: Reactive Oxygen Species

\section{Introduction}

The emergence of chemical molecules was a blessing at once to combat several diseases, but it paved the way for troublous situations like various adverse effects, the emergence of resistance. Researches on new molecules with the least toxic effects and better potency is on its way and more attention is being given upon traditional plants for forcing away the above problems. Nature has bestowed our world with an enormous wealth of medicinal plants. Medicinal plants have been recognized as potential drug candidates. Stevia, a natural sweetener producing medicinal plant having nutritional, therapeutic and industrial importance is being used all over the world. Stevia rebaudiana is a shrub belongs to Asteraceae family and is indigenous to Paraguay, Brazil. It is being cultivated in some parts of Canada, Asia and Europe. Though there are above 200 species of the genus stevia, only stevia rebaudiana gives the sweetest essence [1]. Leaves of Stevia produce diterpene glycosides (stevioside and rebaudiosides), non-nutritive, nontoxic, high-potency sweeteners and may replace sucrose as well as other artificial sweetners, being 300 times sweeter than sucrose [2]. Stevia rebaudiana leaves are usually referred to as candy, sweet and honey leaves. This is due to the production of stevoil glycosides sweetening compounds [3]. It is known for its sweetness imparted by its glycosides without causing any dysregulation. Steviol is the common aglycone backbone of the sweet stevia glycosides that have been analyzed by liquid chromatography coupled with UV, MS and ELS detection [4]. The phytochemical studies concluded the existence of tannins, alkaloids, glycosides, saponins, sterols, triterpenes with various potentials $[5,6]$. Purpose of this review to understand the medicinal potential of stevia and its acceptance as a significant raw material for human diet.

\section{Botanical Description of Stevia}

Stevia is a woody shrub and when it fully matured can reach upto $80 \mathrm{~cm}$ in height. The stevia genus comprises at least 110 species but there may be as many as 300 . Its habitat extends from the southwestern United States to the Brazilian highlands [7]. It is estimated that there are over 250 species of stevia which grows wild around the world. However, sweetening properties have been found in stevia rebaudiana and in some species. Stevia is a 


\section{Current Research in Diabetes \& Obesity Journal}

short day plant that grows up to $1 \mathrm{~m}$ tall. It has sessile, elliptic, 3-4 $\mathrm{cm}$ long leaves. The root system of the plant is extensive, the stem is woody and weak-pubescent at the bottom. It has white flowers with a pale purple throat. They are small in size and arranged in the form of small corymbs [1]. Taxonomic information of stevia rebaudiana is present in Table 1 .

Table 1: Taxonomic information of Stevia rebaudiana.

\begin{tabular}{|c|c|}
\hline \multicolumn{2}{|c|}{ Taxonomic Information } \\
\hline Botanical name & Stevia rebaudiana \\
\hline Kingdom & Plantae \\
\hline Division & Angiosperms \\
\hline Class & Eudicots \\
\hline Order & Asterales \\
\hline Family & Asteraceae \\
\hline Genus & Stevia \\
\hline Species & S. rebaudiana \\
\hline
\end{tabular}

\section{Chemical Description of Stevia}

Diterpene glycosides are responsible for its high sweetening potential of leaves. Steviol glycosides, are extracted and recognized as stevioside, rebaudioside, steviolbioside and dulcoside. Most

Table 2: Medicinal properties of phytochemicals present in stevia.

\begin{tabular}{|c|c|c|}
\hline Phytochemicals & Medicinal Properties & References \\
\hline Phenols & Anti-apoptotic, anti-inflammatory and anti-aging properties of plant & {$[21]$} \\
\hline Saponins & $\begin{array}{c}\text { Anti-bacterial agents, surface active and foaming agents, applied in detergents, used to treat diabetes and } \\
\text { obesity }\end{array}$ & {$[11]$} \\
\hline Flavonoids & $\begin{array}{l}\text { Anti-allergic, anti-cancer, anti-microbial, free radical scavenging activity, prevent oxidative damage and } \\
\text { intestinal disorders }\end{array}$ & {$[12]$} \\
\hline Alkaloids & Pain removing medications & {$[19]$} \\
\hline Tannins & Used in treating diarrhea and dysentery, wound healing properties & {$[31]$} \\
\hline Steroids & Regulate the immune system and reduce the hyper-cholestrolemia & {$[30]$} \\
\hline Coumarins & Prevent hyper-proliferative skin diseases & [31] \\
\hline
\end{tabular}

\section{Nutritional Composition of Stevia Leaves}

Stevia leaves on a dry weight basis provides an energy of $2.7 \mathrm{kcal} / \mathrm{g}$ and it is considered as low calorie sweetener. Benefits related to stevia leaf are mostly due to their nutritional composition because it is a significant source of carbohydrates, protein and crude fiber that maintains the wellbeing and decrease the risk of various diseases. Fat content in dried stevia powder is up to $1.9-4.34 \mathrm{~g} / 100 \mathrm{~g}$ whereas, carbohydrates and protein contents are in range of 52 to 64.06 and 10.0 to 18.0 respectively $[12,13]$. The proximate composition of stevia is presented in Table 2. In stevia leaves main source of energy is carbohydrates due to the presence of poly and fructo-oligosaccharides, which regulates the metabolism of lipid and reduce the sugar level in blood [3]. ample glycoside of stevia is stevioside and is found to be $4-13 \%$ of dry weight in the stevia leaves, rbaudioside is $2-5 \%$ and dulcoside $0.4-0.7 \%$. Stevioside accounts for 4 up to $13 \%$ all glycosides in stevia. It is bittery or stringent when it is tasted. Comparative organoleptic analyses showed that pure stevioside is 300 times sweeter than sucrose at a concentration of $0.4 \%$ [8]. Kroyer [9] reported that steviosides are stable at various processing and storage conditions. Rebaudioside is $250-450$ times sweeter than sucrose and it is found in stevia rebaudiana at $2-5 \%$ of dry matter. It is the most stable of glycosides and has no bitter after taste, in contrast to steviosides. Rebaudioside is metabolised by intestinal microorganisms to stevioside and finally it is transformed to glucose and a molecule of steviol. Apart from diterpene glycosides, sweet leaf also contains diterpenes and triterpenes [10].

\section{Phytochemical Constituents}

Plants accumulate secondary metabolites called phytochemicals to defend themselves against microbial infections or infestations by pests. Phytochemicals are active ingredients which possess therapeutic properties that are considered as a medicine or drug [11]. Srivastava et al. [12] showed the presence of different phytochemicals in stevia leaves extract with their respective solvent systems. The phytochemical properties of bioactive chemicals present in stevia leaves are summarized in Table 2. 
[16]. Metabolization process of rebaudioside in the digestive tract is start by colon microbes which converted it into the stevioside that further metabolized into steviol and glucose. Glucose which is formed in this process directly used by bacteria present in colon rather to absorbed in blood stream. Benefit of using stevia leaves is that after processing there is no accumulation of any by product in human body because all the excess components release through urine. Furthermore, qualitative and quantitative resemblances have been identified among the gut microflora of human body and rats [17]. Another study which was conducted on to the human gastro-intestinal tract determines that that metabolized form of stevia is not modified in low and high concentrations as observed by faeces, study also indicated that much of the steviol glycosides are absorbed and remaining released by urine through kidneys with the help of glucuronide bond. Whereas, minute quantities of glucuronide excreted through fecal mass [18].

Table 3: Proximate and mineral contents of dried stevia leaves.

\begin{tabular}{|c|c|c|c|}
\hline Proximate Parameters & Contents g/100g & Minerals & Iron \\
\hline Moisture & 6.7 & Sodium & 34.2 \\
\hline Ash & 11.5 & Potassium & 254.3 \\
\hline Fat & 4.2 & Calcium & 534.43 \\
\hline Protein & 18 & Magnesium & 465.35 \\
\hline Crude fiber & 14.89 & Phosphorus & 305 \\
\hline Carbohydrates & 30.4 & Chloride & 49.5 \\
\hline
\end{tabular}

\section{Caloric Content of Steviosides}

It has been shown that the human body does not absorb stevioside by the oral route and none of the digestive enzymes of the gastrointestinal tract can degrade stevioside in its aglycone: steviol. It is important to notice that bacteria present in human colon are capable of transforming stevioside to steviol. As steviosides are not absorbed by the human body because majority of it after absorption excreted through urine and remaining minute quantities eliminated through feces, therefore, steviosides are not a source of caloric energy [17]. Several tests of digestion and absorption have been performed with stevioside compounds and the effect of gastric juices and digestive enzymes on them show their inability to degrade the compounds. The in vitro digestibility of steviosides by various digestive enzymes has been examined for many years; studies found that none of the enzymes present in the digestive tract that digest stevioside, it is only hydrolyzed by colon bacteria into both steviol and steviol-16, 17 alpha-epoxide. Later, steviol 16, 17 alpha-epoxide was again converted to steviol, which was excreted from the body in the urine as steviol glucuronide [19]. This whole process also describes why stevia rebaudiana does not provide calories to the human body.

\section{Effects of Steviosides Consumption on Human Health}

About the characteristics of $S$. rebaudiana beyond its sweetening potential, several studies have been published where antimicrobial, antifungal, hepatoprotective, hypoglycaemic (aqueous extract), antitumor, anti-rotavirus, anti-HIV, antihypertensive, antiviral and other effects are attributed to it. Other popular applications of stevia and stevioside (mainly in Latin America and the East) include stimulation of alertness and as a supplement against fatigue; it is also attributed an improvement in the process of digestion and other gastrointestinal functions; in addition to regulating blood glucose levels, help in the recovery of liver, pancreas and spleen [18]. Many of these effects are attributed to the phenolic compounds present in the plant (in the leaves and, to a lesser extent in the stem), said compounds are commonly found in both edible and inedible plants. They are important in the plant for the normal development of growth and defense against the attack of bacteria, parasites, infections, and injuries. Also, the presence of these compounds in injured plants can have an important effect on oxidative stability and microbial safety. Although phenolic compounds have no known nutritional function, they can be important for human health because of their antioxidant potential [20].

\section{Clinical Trials on Stevia rebaudiana}

Although the information regarding the reported effects of stevia rebaudiana is vast. Various studies with different dosage, duration and results regarding clinical trials conducted for different durations (Table 4). Clinical studies indicate the provision of stevia in various forms like powder, aqueous and stevioside to human and STZ rats. Stevia significantly shown the hypoglycemic and weight reduction properties.

\section{Medicinal Potential of Stevia}

\section{Anti-hyperglycemic}

Diabetes mellitus is a metabolic disorder characterized by chronic hyperglycemia accompanied by disturbances in carbohydrate, protein and fat metabolism, due to either insufficient insulin secretion or insulin insensitivity or both. Though Stevia rebaudiana is mainly used as a sweetening agent in foods and beverages, they do not induce a glycaemic response 
when ingested, rather than it exerts antidiabetic action by the enhanced secretion of insulin from the beta cells of pancreas and promoting glucose uptake by enhancing insulin sensitivity of peripheral tissues. Stevioside also hinders the production of glucose by preventing the secretion of glucagon secretion $[23,24]$. The molecular mechanism of action of steviol glycosides as it modulating pancreatic beta cell function by potentiating TRPM5 (Transient receptor potential cation channel subfamily M member 5), basically a calcium activated cation channel, expressed on beta cells and peripheral entero-endocrine cells in the gut by accelerating insulin release in response to glucose stimulation. Steviol, stevioside, rebaudioside are not the direct agonist of TRPM5, but the steviol moiety is responsible for interacting with the protein. Besides, these glycosides can be used as antihyperglycaemic agents, they are novel leads to the development of antidiabetic drugs targeting TRPM5. Further, these agents didn't produce hypoglycemia, as seen with synthetic agents and hence will be a great boon for diabetic patients [25]. Steviol glycosides are able to act as ligands of the insulin receptor (IR or IGF-IR) activating the P13k/Akt pathway. Upon activation, signal leads to the Glut 4 translocation from an intracellular pool to the plasma membrane, allowing glucose entry into cells and thus mimics the action of insulin. Biscuits incorporated with stevia was found to inhibit $\alpha$-glucosidase activity. Aqueous extract of stevia produced anti-hyperglycemic and restore liver and muscle glycogen levels in hyperglycemia-induced rabbits by immobilization stress [26].

Table 4: Effective dosage of Stevia rebaudiana on clinical trials.

\begin{tabular}{|c|c|c|c|c|}
\hline Subjects & Dose & Duration & Results & References \\
\hline Diabetic human & $1000 \mathrm{mg}$ stevioside & One day & $\begin{array}{l}\text { Reduce postprandial glucose } 20 \% \text { than } \\
\text { control }\end{array}$ & [18] \\
\hline $\begin{array}{l}\text { Streptozotocin (STZ) induced } \\
\text { diabetic rats }\end{array}$ & $\begin{array}{c}250,500 \text { and } 750 \mathrm{mg} / \mathrm{kg} / \text { day aqueous } \\
\text { extract of stevia }\end{array}$ & 30 days & $\begin{array}{l}500 \text { and } 750 \mathrm{mg} / \mathrm{kg} / \text { day lowers blood } \\
\text { glucose }\end{array}$ & [20] \\
\hline $\begin{array}{l}\text { Diabetic and hypertensive sub- } \\
\text { jects (30-55 years) }\end{array}$ & $0.5-1$ gram $/ \mathrm{kg}$ stevia powder & 40 days & $\begin{array}{l}\text { Stevia powder has hypoglycemic and } \\
\text { hypotensive effect }\end{array}$ & {$[21]$} \\
\hline STZ induced diabetic rats & $\begin{array}{c}300,400,500 \mathrm{ppm} / \mathrm{kg} \text { stevia aqueous } \\
\text { extract }\end{array}$ & 60 days & $\begin{array}{l}\text { Decrease body weight by managing } \\
\text { calories }\end{array}$ & {$[22]$} \\
\hline
\end{tabular}

Comparison of stevia and pioglitazone, a thiazolidinedione, both of them having antioxidant properties too can act as ligands on PPAR- $\gamma$ (peroxisome proliferator-activated receptor- $\gamma$ ), a nuclear hormone receptor and induce insulin secretion and control the level of blood glucose. The mRNA expression of PPAR $-\gamma$ can be increased by both stevia and pioglitazone. The hypoglycemic effect is also aided by its antioxidant nature [27]. Reduction in the level of inflammatory cytokine IL-6, which potentiate the elevation of insulin resistance and therefore helpful in type 2 diabetes [28]. Stevia could control the neuronal synaptic plasticity in conditions of metabolic disorders induced by the high consumption of dietary fructose by influencing NOX-(NADPH oxidase level) specific targets and thus have a neuroprotective role [29].

\section{Antioxidant activity}

Oxidative damage to biological materials is inflicted on biomolecules such as proteins, nucleic acid, lipids, and carbohydrates. Oxidative stress happens when there occurs a disproportion among the secretion of reactive oxygen species (ROS) and the capability of human body to voluntarily detoxify the free radicals to repair the subsequent impairment. In vitro, the antioxidant activity of stevia extract was confirmed by diphenyl1-picrylhydrazyl-hydrate (DPPH) radical scavenging assay, FRAP (ferric ion reducing activity) assay, and phosphomolybdenum assay [30,31]. Both methanolic and aqueous extract of dried stevia leaves is enriched with polyphenols like hesperidin, ellagic acid, chlorogenic acid, eugenol, coumarin, vanillin and flavonoids and hence can be used as a significant source of antioxidant in food and beverages and a promising candidate for diseases like diabetes, cancer, neural disorders, arthritis and aging which is caused by the production of ROS. The potentiality of stevia antioxidants is able to supersede the synthetic antioxidants like BHA (Butylated hydroxyanisole) and BHT (Butylated hydroxytoluene), which recently limited in its use due to their carcinogenic potential [32].

Hydrogen peroxide, an abiotic stress elicitor resulted in an increased steviol glycoside production such as rebaudioside and stevioside and non-enzymatic antioxidants that play a defensive role against an oxidative stress induced by hydrogen peroxide [31]. The antioxidant activity of phenolic compounds is due to the radical scavenging by donationg hydrogen. Other radical quenching mechanisms include electron donation and singlet oxygen quenching. The antioxidant effects of flavonoids are ascribed to their power to neutralize the free radicals, chelate metal catalyst, activate antioxidant enzymes, reduce alpha-tocopherol radicals and prevent the actions of oxidases. A significant decrease in the cellular oxidation biomarkers like protein carbonyl content (PCC), antioxidant enzymes (SOD and CAT) was seen in the presence of stevia glycosides in $\mathrm{CCl}_{4}$ induced oxidative stress in a fish model (Cyprinus carpio) [33].

\section{Anti-hyperlipidemic and hypotensive effect}

Aqueous extract of stevia rebaudiana exerts a hypolipidemic effect by decreasing cholesterol and fatty acid synthesis, 
attenuating total cholesterol, triglycerides, and LDL levels and elevating HDL cholesterol [23]. Stevia leaves help in regulating the blood pressure by relaxing arteries and prevent the buildup of calcium on artery walls, that promotes vasodilation and reduces total peripheral resistance and volume of extracellular fluid as result of elevated natriuresis and diuresis. Both hypolipidemic and hypotensive effect exerts a cardio-protective action [34].

\section{Antitumor effect}

Stevioside has shown a marked effect against various cancers like skin cancer, ovarian cancer and breast cancer as demonstrated in various cell line studies. The mechanisms for antitumor effects as it mediated the apoptosis induced by reactive oxygen species by scavenge free radicals, increased the expression of apoptotic proteins like Bax, Bc1-2, caspase 9 and reducing the cell viability by inhibiting DNA synthesis and inducing cell apoptosis. Iso-steviol, a breakdown product of stevioside, manifested an inhibitory activity against the enzymes DNA polymerase and DNA topoisomerase II and inactivates P13K/AKT signaling pathway by inhibiting phosphorylation of P13 and AKT. From the methanolic extract of Stevia one compound was isolated and further confirmed by NMR to be centaureidin, which has an antimitotic effect to be used for tumor therapy [31,34].

\section{Nephro-protective}

Both stevioside and extracts of stevia show nephroprotective action due to the coinciding activities like suppression of oxidative stress, inflammation, and apoptosis. Renal hypertrophy, glomerular hyper-filtration are two known complications in the initial stages of diabetes mellitus as characterized by then increased cortical volume (80\%) and its subcomponents PCT (Proximal Convoluted Tubule), DCT (Distal Convoluted Tubule), glomeruli, interstitial tissue rather than medullary volume. The molecular mechanism of these two complications includes the production of Transforming growth factor $\beta$ (TGF- $\beta$ ) by mesangial components and overproduction of free radicals following hyperglycemia. Expression of inducible nitric oxide synthase NOS in response to cytokines [35]. Stevia and its glycosides attenuate not only diabetes related kidney injury but also cisplatin-induced nephrotoxicity. Cisplatin is a chemotherapeutic agent which exerts its action by activating cell cycle arrest, apoptosis and DNA repair. The mechanism of nephron-protective action by attenuation of oxidative and nitro-sative stress, anti-inflammatory activity by decreasing $\mathrm{p} 65$ and TNF- $\alpha$ expression, anti-apoptotic effect by suppressing the release of caspase-activating proteins and restoring cell cycle by reduced p21 expression and increased cyclin D1 expression by suppressing ERK1/2 activation, associated with apoptosis and cell cycle arrest [36].

\section{Hepato-protective}

The antioxidant potential of stevia can be utilized to alleviate hepatic injury like cirrhosis, hepatic carcinoma which is induced by the oxidative stress. The hepato-protective ability of stevia is confirmed against $\mathrm{CCl}_{4}$ induced and lipopolysaccharide-induced injury in rat and chicken embryo model. The mechanism of $\mathrm{CCl}_{4}$ induced liver injury is its metabolic activation by $\mathrm{CYP}_{450}$ and forms tri-chloro-methyl free radical $\mathrm{CCl}_{3}$. These free radicals stimulate lipid peroxidation, protein covalent binding. Glutathione depletion, and disturbance of calcium and iron ions ultimately leading to cell death. Lipopolysaccharide is an endotoxin, a potent inflammagen and the glycolipid component of the cell membrane of gram-negative bacteria. It exerts liver injury by releasing inflammatory cytokines like TNF- $\alpha$ (Tumor Necrosis Factor $-\alpha$ ), IL-1 $\beta$, IL-6 (Interleukins) \& ROS [37]. The molecular mechanism of hepato-protective action of stevia is induction of Nrf2 pathway which is an endogenous pathway to reduce the level of reactive metabolites. Immunomodulatory action- by inhibiting NF- $\kappa \beta$ that leads to the downregulation of pro-inflammatory cascade and thereby prevents necrosis, cholestasis, and preservation of liver parenchyma structure and function [38].

\section{Antibacterial and antifungal activity}

Plants have provided a source of inspiration for novel drug compounds to many scientists. Scientists used different solvent extracts (methanol, ethanol, ethylacetate, acetone, petroleumether, chroloform) to investigate the antimicrobial activity of stevia leaves. Stevia is thought to inhibit the growth of certain bacteria and other infectious organisms. In some antimicrobial activity screening studies, these extracts exhibited susceptibility enough to inhibit the growth of certain pathogenic bacteria such as Escherichia coli, Bacillus subtilis, Salmonella typhi, Enterococcus faecalis, Proteus mirabilis, Pseudomonas aeruginosa, Staphylococcus aureus, Vibrio cholerae, Aeromonas hydrophila [19]. Antifungal activity was observed against Aspergillusniger, Penicillium chrysogenum, Alternariasolani. Fusariumoxysporum showed maximum zone of inhibition by methanolic plant extracts of stevia rebaudiana in the study of Arya et al. [39]. Therefore, plant extracts and phytochemicals with known antimicrobial properties can be of great significance in therapeutic treatments. The presence of phytochemicals in leaves might have contributed to the antibacterial activity [21].

\section{Conclusion}

Stevia rebaudiana has become an important plant that needs to be commercialized without no time because of its medicinal and therapeutic applications. Constituents of honey leaves can be used directly or in raw form by human body and provide various physiological benefits. Dried stevia leaves powder is also a good source of major and minor nutrients and it is also well known as an efficient medication for curing chronic diseases. Future researches also needed to determine its further positive potentials against diseases and to evaluate its accurate daily intake which is suitable for human consumption without causing any negative consequences. 


\section{Current Research in Diabetes \& Obesity Journal}

\section{References}

1. Adesh AB, Gopalakrishna B, AkkiKusum S, Tiwari OP (2012) An overview on stevia: a natural calorie free sweetener. Int J Adv Pharma Biol Che 1: 362-368.

2. Yadav AK, Singh S, Dhyani D, Ahuja PS (2011) A review on the improvement of stevia [Stevia rebaudiana (Bertoni)]. Can J Plant Sci 91: 127130

3. Braz-De-Oliveira A, Goncalves RAC, Chierrito TPC, Souza L, Gorin PAJ, et al. (2011) Structure and degree of polymerisation of fructooligosaccharides present in roots and leaves of stevia rebaudiana bertoni. Food Chem 129(2): 305-311.

4. Cacciola F, Delmontea P, Jaworska K, Dugo P, Mondello L, et al. (2011) Employing ultra-high pressure liquid chromatography as the second dimension in a comprehensive two-dimensional system for analysis of stevia rebaudiana extracts. J Chromat 1218: 2012-2018.

5. Raut D, Aruna K (2017) Antimicrobial activity of stevia rebaudiana against antibiotic resistant ESBL producing uropathogens and evaluation of its antioxidant activity. Int J Adv Res Biol Sci 4: 110-118.

6. Miranda-Arambula M, Olvera-Alvarado M, LoboSanchez M, Perez-Xochipa I, Rios-Cortes AM (2017) Antibacterial activity of extracts of stevia rebaudiana bertoni against staphylococcus aureus, staphylococcus epidermidis and pseudomonas aeruginosa. J Med Plant Res 11: 414-418.

7. Goyal S, Samsher R (2010) Stevia a bio-sweetener: a review. Int J Food Sci Nutr 61: 1-10.

8. López-Carbón V, Sayago A, González-Domínguez R, Fernández-Recamales Á (2019) Simple and efficient green extraction of steviol glycosides from stevia rebaudiana leaves. Food 8(9): 402-406.

9. Kroyer G (2010) Stevioside and stevia-sweetener in food, application, stability and interaction with food ingredients. J verb lebensm 5: 225229.

10. Marcinek K, Krejpcio Z (2015) Stevia rebaudiana bertoni-chemical composition and functional properties. Acta Sci Pol Technol Aliment 14(2): $145-152$

11. Shakya AK (2016) Medicinal plants: future source of new drugs. Int Herbl Med 4: 59-64.

12. Srivastava S, Chouhan DES, Chawla P (2016) Proximate and phytochemical analysis of stevia leaves powder. Int Ayurved med J 4: 2476 2480 .

13. Gasmalla MAA, Yang R, Issoufou A, Hua X (2014) Nutritional composition of stevia rebaudiana bertoni leaf: effect of drying method. Trop J Pharm Res 13: 61-65.

14. Kobus-Moryson M, Gramza-Michalowska A, Kobus-Cisowska J, Korczak J (2014) Contents of selected elements in extracts from sweet leaf (stevia rebaudiana Bertoni). Probl Hig Epidemiol 95: 445-448.

15. Ahmed SR, Mukta S (2017) Review on stevia rebaudiana as a non-caloric natural sweetener producing plant. J Syl Agric Uni 4: 15-25.

16. Shuvo MMA, Al-Mamun M, Chowdhury T, Absar N, Hasanuzzaman M (2015) An assessment of major nutritional components and some secondary metabolites of in vitro propagated stevia rebaudiana (cultured in Bangladesh) plant leaves dry powder. Int J Applied Sci Biotechnol 3: 721-26.

17. Gupta E, Purwar S, Sundaram S, Rai GK (2013) Nutritional and therapeutic values of stevia rebaudiana: a review. J Med Plant Res 7: 334353.

18. Escutia-López KN, Sánchez-Pardo ME (2019) A comprehensive review on the nutritional and therapeutical aspects of stevia rebaudiana ber- toni. J Appl Biotechnol Bioeng 6: 297-302.

19. Salehi B, López MD, Martínez-López S, Victoriano M, Sharifi-Rad J, et al. (2019) Stevia rebaudiana bertoni bioactive effects: from in vivo to clinical trials towards future therapeutic approaches. Phytotherap Res 33(11): 2904-2917.

20. Shannon M, Rehfeld A, Frizzell C (2016) In vitro bioassay investigations of the endocrine-disrupting potential of steviol glycosides and their metabolite steviol, components of the natural sweetener stevia. Mol cell endocrinol 427: 65-72.

21. Singh DP, Kumari M, Prakash HG, Rao GP, Solomon S (2019) Phytochemical and pharmacological importance of stevia: a calorie-free natural sweetener. Sugar Tech 21: 227-34.

22. Ahmad U, Ahmad RS (2018) Antidiabetic property of aqueous extract of stevia rebaudiana bertoni leaves in streptozotocin-induced diabetes in albino rats. BMC Compl Alter med 18: 179-182.

23. Scaria A, Kamath JV, Chakraborty M (2017) Antihyperglycemic, Antioxidant, Anti hyperlipidemic \& nephroprotective effect of stevioside in diabetic rats. Int J Ayurved Med 8: 178-813.

24. Ilić V, Vukmirović, Tilinović N, Čapo I, Arsenović M, Mili ašević B (2017) Insight into anti-diabetic effect of low dose of stevioside. Biomed Pharmaco 90: 216-221.

25. Prata C, Zambonin L, Rizzo B, Maraldi T, Angeloni C, et al. (2017) Gly cosides from stevia rebaudiana bertoni possess insulin-mimetic and antioxidant activities in rat cardiac fibroblasts. Oxidat med cell longev 11: $140-148$.

26. Aghajanyan A, Movsisyan Z, Trchounian A (2017) Antihyperglycemic and antihyperlipidemic activity of hydroponic stevia rebaudiana aqueous extract in hyperglycemia induced by immobilization stress in rabbits. BioMed Res int 10: 120-123.

27. Assaei R, Mokarram P, Dastghaib S, Darbandi S, Darbandi M, et al (2016) Hypoglycemic effect of aquatic extract of stevia in pancreas of diabetic rats: PPAR $\gamma$-dependent regulation or antioxidant potential. Avi J Med Biotechnol 8: 65-69.

28. Bayat E, Dastgheib S, Egdar S, Mokarram P (2017) Effect of the aquatic extract of stevia on the serum level of interleukin-6 in streptozotocin-nicotinamide induced diabetic rats. Shiraz E-Med J 18: 160-170.

29. Chavushyan VA, Simonyan KV, Simonyan RM, Isoyan AS, Simonyan GM et al. (2017) Effects of stevia on synaptic plasticity and NADPH oxidase level of CNS in conditions of metabolic disorders caused by fructose. BMC Compl Alter Med 17(1): 540-543.

30. Najafian S, Moradi M (2017) Polyphenolic compounds (HPLC analysis) and antioxidant activity of stevia rebaudiana (Asteraceae) by FRAP and DPPH assay in greenhouse and free space condition. Int J Farm Allied Sci 6: 49-55.

31. Mohammad AM (2018) In vitro determination of total phenolics, flavonoids and free radical scavenging activities of stevia rebaudiana dry leaves powder in different solvents extract. EC Nutr 13: 71-78.

32. Yücesan B, Gurel E (2018) Hydrogen peroxide-induced steviol glycosides accumulation and enhancement of antioxidant activities in leaf tissues of stevia rebaudiana bertoni. Sugar Tech 20: 100-104.

33. Ruiz-Ruiz JC, Moguel-Ordoñez YB, Matus-Basto AJ, SeguraCampos MR (2015) Antidiabetic and antioxidant activity of stevia rebaudiana extracts and their incorporation into a potential functional bread. J Food Sci Technol 52: 7894-7903.

34. Li XY, Lu WM, Shen WF, Wu Y, Liu YP, et al. (2017) Growth inhibitory effect of stevioside on ovarian cancer through AKT/ERK pathway. Biomed Res 28: 1820-1827. 


\section{Current Research in Diabetes \& Obesity Journal}

35. Potocnjak I, Broznic D, Kindl M, Kropek M, Vladimir Knezevic S, et al (2017) Stevia and stevioside protect against cisplatin nephrotoxicity through inhibition of ERK1/2, STAT3, and NF-kB activation. Food Chem Toxicol 107: 215-225.

36. Hagh-Nazari L, Goodarzi N, Zangeneh MM, Zangeneh A, Tahvilian R, et al. (2017) Stereological study of kidney in streptozotocin-induced diabetic mice treated with ethanolic extract of Stevia rebaudiana (bitter fraction). Comp Clinic Pathol 26: 455-463.

37. Wang Y, Li L, Wang Y, Zhu X, Jiang M, Song E, Song Y (2018) New application of the commercial sweetener rebaudioside as a hepatoprotective candidate: induction of the Nrf2 signaling pathway. Europ J Pharmacol 8: 128-137.
38. Latha S, Chaudhary S, Ray RS (2017) Hydroalcoholic extract of stevia rebaudiana bertoni leaves and stevioside ameliorates lipopolysaccharide-induced acute liver injury in rats. Biomed Pharmaco 95: 10401050.

39. Arya A, Kumar S, Kasana MS (2012) In vitro regeneration of stevia and evaluation of antimicrobial and antiprotozoal properties of regenerated calli and plants. Elect J Plant Breed 3: 916-924.

Your next submission with Juniper Publishers
will reach you the below assets
- Quality Editorial service
- Swift Peer Review
- Reprints availability
- E-prints Service
- Manuscript Podcast for convenient understanding
- Global attainment for your research
- Manuscript accessibility in different formats
- Unceasing customer service
Track the below URL for one-step submission
https://juniperpublishers.com/online-submission.php

